\title{
Klasifikasi Kanker Payudara menggunakan Ekstraksi Ciri Metode Statistik
}

\author{
Muhammad Fuad, Wahyudi Setiawan \\ Fakultas Teknik, Universitas Trunojoyo \\ Jln. Raya Telang, PO BOX 2 Kamal, \\ Bangkalan, Jawa Timur \\ fuad@trunojoyo.ac.id, wsetiawan@trunojoyo.ac.id
}

Diterima: 16 September 2016. Disetujui: 26 Oktober 2016. Dipublikasikan: Nopember 2016

\begin{abstract}
Abstrak - Kanker Payudara merupakan penyakit degeneratif yang menyerang jaringan pada payudara. Tingginya penderita kanker payudara disebabkan karena minimnya informasi. Penderita dengan stadium akhir sering dijumpai akibat dari ketiadaan pencegahan dan pengobatan di stadium awal. Pemeriksaan dini diperlukan untuk mengatasi perkembangan penyakit lebih lanjut. Pemeriksaan kanker payudara disebut juga dengan mammografi. Mammografi merupakan teknik penyinaran dengan sinar $\mathrm{X}$ dosis rendah untuk mendapatkan citra. Citra mammogram dapat membantu dokter untuk memastikan keberadan sel-sel kanker yang ada dalam payudara. Citra yang telah didapat dari proses mammografi akan dilakukan ekstraksi ciri. Ekstraksi ciri merupakan proses untuk mendapatkan ciri-ciri tertentu sebagai pembeda dari ciri yang lain. Pada penelitian ini ekstraksi ciri menggunakan metode statistik yaitu mean, standar deviasi, variance, skewness, kurtosis dan entropy. Klasifikasi menggunakan $k$ Nearest Neighbour. Citra uji berasal dari MIAS (Mammographics Images Analysis Society). Dataset yang digunakan sebanyak 15 citra mammografi, terdiri dari 3 kelas yaitu normal, jinak dan ganas .
\end{abstract}

Kata Kunci : kanker payudara, mammografi, citra, metode statistik, $k$-nearest Neighbour

\section{PENDAHULUAN}

Medical imaging merupakan teknik pengambilan citra bagian dalam organ tubuh tanpa melakukan pembukaan atau sayatan pada tubuh. Teknik ini cukup dikenal di kalangan kedokteran diantaranya melalui sinar X (rontgen), Computer Tommography Scanner (CT-Scan), Ultrasonogarphy (USG), citra fundus untuk retina dan mammografi.

Pada penelitian ini akan dibahas tentang klasifikasi citra mammogram untuk mendeteksi kanker payudara. Kanker payudara merupakan salah satu kanker dengan jumlah penderita no mor 2 (dua) tertinggi di Indonesia. Kanker payudara berawal dari saluran air susu atau dari lobulus yang kemudian menyebar ke seluruh jaringan lemak yang ada di payudara. Kanker payudara berawal dari sel-sel tubuh yang seharusnya mati namun tetap tumbuh dan membesar. Sel-sel tubuh ini bermutasi dengan tumbuh tidak normal. Terdapat dua tipe kanker payudara yaitu sel kanker yang berada dalam saluran air susu (karsinoma in situ atau non invasive) dan sel kanker yang telah menyebar dan menembus dinding saluran air susu (infiltrat atau invasive). Kanker payudara sangat mungkin disembuhkan jika terdeteksi padastadium awal. Gaya hidup yang baik, olahraga teratur, makan makanan seimbang, istirahat cukup, tidak mengkonsumsi alkohol serta menjauhi radikal bebas merupakan beberapa hal yang direkomendasikan untuk menghindari penyakit in $\mathrm{i}$ [1].

Teknik mammografi merupakan teknik untuk mendapatkan citra yang terindikasi kanker payudara melalui sinar $\mathrm{X}$ dosis rendah. Teknik mammografi membantu tenaga medis dalam melakukan analis is terhadap citra mammogram.

Penelitian yang dilakukan oleh Tintu dan Paulin membahas tentang klasifikasi citra mammografi menjadi 2 kelas yaitu normal dan teridentifikasi kanker. Penelitian ini menggunakan data dari Wisconsin Prognostic Breast Cancer (WPBC). Metode klasifikasi yang digunakan yaitu Fuzzy C Means. Persentase keberhasilan klasifikasi sebesar $97,13 \%$ [2].

Penelitian oleh Elsayad dan Elsalamony membahas tentang perbandingan metode klasifikasi antara decision tree models C5.0 dan Support Vector Machine. Dataset yang dilakukan pengujian menggunakan Wisconsin Breast Cancer Dataset (WBCD). Hasil Klasifikasi menunjukkan persentase $96 \%$ [3].

Penelitian oleh Salama dan Zeid, membahas tentang penggunaan 3 dataset yaitu Wisconsin Breast Cancer (WBC), Wisconsin Diagnosis Breast Cancer (WDBC), Wisconsin Prognosis Breast Cancer $(W P B C)$. Metode klasifikasi yang digunakan yaitu Decision Tree J48, Multilayer Perception (MLP), Naive Bayes, Sequential Minimal 
Optimization dan Instance Based for K-Nearest Neighboor. Keakuratan klasifikasi yang didapatkan sebesar $77,32 \%$ [4].

Penelitian oleh Zaheeruddin, et al. tentang Deteksi Kanker payudara menggunakan mammografi menggunakan beberapa tahapan yaitu preprosesing, marker based watershield algorithm, Tumor Segmentation (ROI), Converting ROI into label matrix dan parameter extraction. Tahapan penelitian ini dinamakan Marker-Controlled Watersheld Segmentation [5].

Penelitian oleh Cruz menggunakan beberapa tahapan pengenalan pola diantaranya image enhancement menggunakan Contrast Limited Adaptive Histogram Equalizatin (CLA HE), Contrast Stretching, Adaptive Neighbourhood Contrast enhancement, unsharp masking, adaptive unsharp masking dan homomorphic filter. Tahapan selanjutnya yaitu image segmentation menggunakan adaptive threshold, adaptive threshold followed by morphological operators, threshold and difference of Gaussians, region growing of selected areas, active contours of selected areas and edge detection. Klasifikasi menggunakan $k$-Nearest Neighbour [6].

Pada penelitian yang digunakan oleh Luna Benoso, digunakan Dataset MIAS. Tahapan penelitian menggunakan Highboost filre, binerisasi dengan thresholding, Removing connected component corresponding, eliminasi noise dengan locating connected segment larger area [7].

Penelitian oleh Satoso, dkk. menggunakan Fuzzy Inference System sebagai klasifikasi. Tahapannya adalah preprosesing menggunakan wiener filter dan ekualisasi histogram. Ekstraksi fitur menggunakan mean, standar deviasi, entropy, skewness, kurtosis [8]. Pada penelitian oleh Ivy dkk., tahapan preprosesing menggunakan Two Level $D W T$, curvelet transform, set of ROI. Klasifikasi menggunakan Euclidian Distance [9].

Pada penelitian oleh Maitra, dkk., menggunakan beberapa metode segmentasi menggunakan Breast ROI diantaranya medio lateral oblique (MLO), Binary Homogeneity Enhancement Algorithm (BHEA), Innovative Approach for Edge Detection (EDA), Breast Boundary Detection Algorithm (BBDA), Breast Homogeneity (BHEA), Pectoral muscle Detection Algorithms, Anatomical Segmentation of Breast ROI (ASB) dan Region Growing Algorithm (RGA). Dari hasil ujicoba menunjukkan akurasi $99,87 \%$, Dice similarity coeffisien $87,96 \%$, error rate 00,12\%, Sensitivity $94,21 \%$, spesifisitas $92,44 \%$ [10].

Penelitian oleh Mane dan Kuhalli, juga menggunakan dataset MIAS. Preprosesing menggunakan Contrast Enhancement, Ekstraksi fitur menggunakan gabor, 2D Wavelet dan PCA.
Klasifikasi menggunakan SVM [11]. Penelitian lain yang dilakukan oleh Shesadri menggunakan metode statictical algorithm, segmentasi dan reliability image [12].

Sistem yang dibangun terdiri dari ekstraksi ciri dan klasifikasi. Ekstraksi ciri (feature extraction) adalah tahapan untuk memunculkan ciri dan mereduksi dimensi citra dari dimensi tinggi ke dimensi lebih rendah. Teknik ekstraksi ciri yang handal merupakan kunci utama dalam penyelesaian masalah pengenalan pola. Pada penelitian oleh Clark, dilakukan ekstraksi ciri menggunakan metode statistik yaitu mean, standar deviasi, variance, Skewness, Kurtosis dan Entropi. Klasifikasi menggunakan $k$-Nearest Neighbour dengan Euclidian Distance. Klasifikasi terdiri dari 3 kelas yaitu normal, jinak (benign) dan ganas (malignant). Normal berarti pada mammogram tidak didapati sel kanker. Benign berarti pada mammogram terdapat pembentukan sel kanker awal. Sel kanker tidak berpengaruh ke jaringandi sekitarnya. Biasanya sel kanker jen is ini dapat diangkat dan pasien dapat disembuhkan. Sedangkan malignant berarti pada mammogram terdapat sel kanker ganas yang merusak jaringan disekitarnya. Pada fase ini, biasanya sel kanker tumbuh cepat dan dapat menyebabkan kematian pada pasien [13].

\section{METODOLOGI PENELITIAN}

Gambaran umum sistem meliputi diagram alir proses pelatihan dan pengujian. Pada proses pelatihan, semua data latih dilakukan pelatihan agar mendapatkan nilai yang sesuai dengan proses pengujian. Pelatihan dilakukan dengan variasi jumlah data latih. Sama halnya dengan skenario pelatihan, pengujian dilakukan dengan variasi jumlah data yang kemudian akan diproses untuk mencocokkan dengan data yang telah diklasifikasikan pada kelas tertentu.

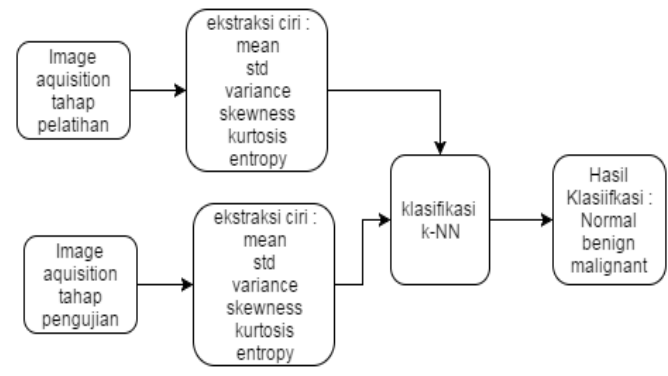

Gambar 1. Bagan Klasifikasi Deteksi Kanker Payudara

Penelitian ini terdiri dari 2 bagian yaitu pelatihan dan pengujian. Setiap bagian terdiri dari 2 tahap yaitu ekstraksi ciri dan klasifikasi. Metodologi penelitian yang dibuat, terdapat pada Gambar 1 . 


\section{A. Ekstraksi Ciri}

Ekstraksi ciri merupakan suatu pengambilan ciri dari suatu objek citra yang merupakan nilai unik pembeda dengan objek yang lain. Ekstraksi ciri metode statistik terdiri dari mean, standar deviasi, variance, Skewness, Kurtosis dan Entropi. Ciri-ciri metode statistik menunjukkan ciri histogram pada citra. Histogram adalah tampilan grafis tentang sebaran frekuensi intensitas warna dari citra. Histogram merupakan salah satu metode ekstraksi ciri lokal yang menggunakan fungsi-fungsi statistik untuk menunjukkan ciri-ciri dari suatu citra [14]. Gambar 2,3 dan 4 merupakan contoh dari citra mammogram dengan histogramnya.
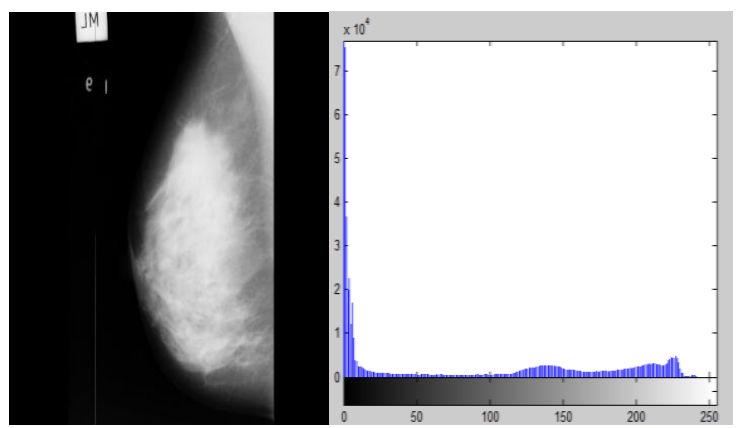

Gambar 2 Citra Mammogram Normal Mdb003.Jpg dan Histogramny a
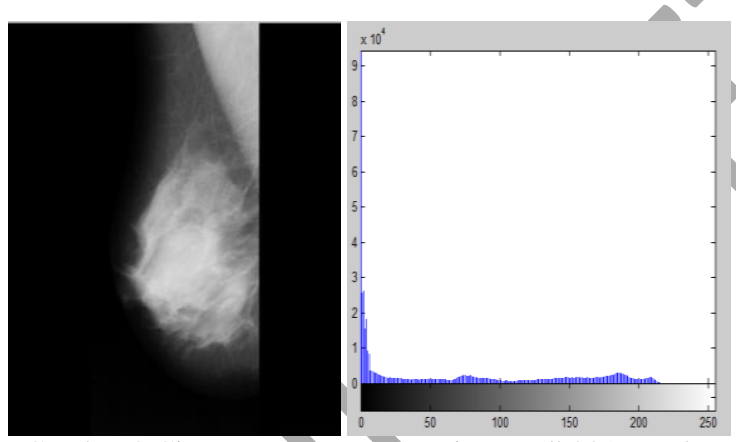

Gambar 3 Citra Mammogram Benign Mdb001.Jpg dan Histogramnya
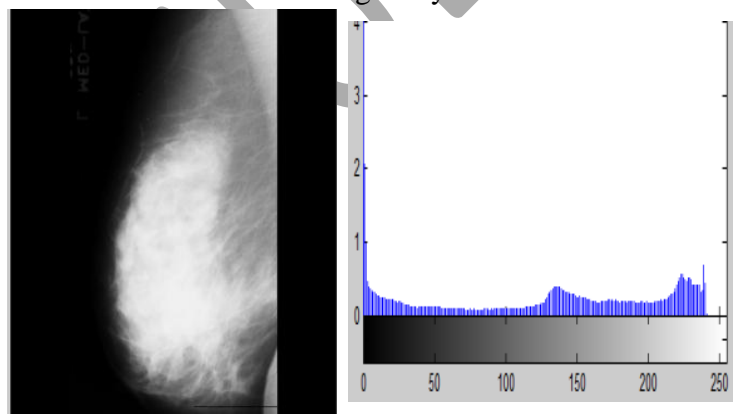

Gambar 4 Citra Mammogram Malignant Mdb105.Jpg dan Histogramny a

Beberapa metode statistik yang digunakan untuk ekstraksi ciri diantanya yaitu [15] dan [16] :

\section{Mean}

Mean adalah ukuran rata-rata intensitas citra.

$$
\mu=\sum_{n=0}^{N} f_{n} p\left(f_{n}\right)
$$

2. Standar deviasi

Standar deviasi merupakan ukuran rata-rata kontras.

$$
\sigma=\sqrt{\mu_{2}(z)}=\sqrt{\sigma^{2}}
$$

3. Variance

Variance merupakan variasi elemen suatu citra.

$$
\alpha_{2}=\sum_{n=0}^{N}\left(f_{n}-\mu\right)^{2} p\left(f_{n}\right)
$$

\section{Skewness}

Skewness merupakan kemencengan relatif dari kurva histogram citra

$$
\alpha_{3}=\frac{1}{\sigma^{3}} \sum_{n=0}^{N}\left(f_{n}-\mu\right)^{3} p\left(f_{n}\right)
$$

\section{Kurtosis}

Kurtosis merupakan keruncingan relatif dari kurva histogram citra

$$
\alpha_{4}=\frac{1}{\sigma^{4}} \sum_{n=0}^{N}\left(f_{n}-\mu\right)^{4} p\left(f_{n}\right)-3
$$

\section{Entropy}

Entropy merupakan bentuk ketidakteraturan (randomless) dari suatu citra

$$
H=-\sum_{n=0}^{N} p\left(f_{n}\right) \cdot{ }^{2} \log p\left(f_{n}\right)
$$

Dimana: $f_{n} \quad=$ nilai intensitas keabuan

$$
\begin{aligned}
& p\left(f_{n}\right)=\text { nilai histogram } \\
& \mu \quad=\text { mean }
\end{aligned}
$$

\section{B. Klasifikasi menggunakan $k-N N$}

Klasifikasi pada penelitian ini menggunakan metode k-Nearest Neigbor Euclidian Distance. k$\mathrm{NN}$ bekerja mencari jarak terdekat sejumlah nilai $\mathrm{k}$ yang ada. Selanjutnya dari beberapa nilai yang terpilih akan terlihat pola dari objek lebih banyak terklasifikasi menjadi kelas tertentu. Algoritma kNN adalah sebagai berikut [16]:

1. Tentukan nilai $\mathrm{k}$

2. Hitung jarak setiap data pelatihan dengan data yang diujicobakan menggunakan euclidian distance

$$
\begin{gathered}
d_{n}=\sqrt{\left(x_{1}-x_{2}\right)^{2}+\left(y_{1}-y_{2}\right)^{2}+\cdots+\left(z_{1}-z_{2}\right)^{2}} \\
\text { dengan : } \quad=\text { jarak citra latih ke 1..n den gan citra uji } \\
\text { d } \quad \text { komponen citra latih } \\
\mathrm{x}_{1}, \mathrm{y}_{1} \ldots \mathrm{z}_{1} \quad \text { omponen citra uji } \\
\mathrm{x}_{2}, \mathrm{y}_{2}, \ldots \mathrm{z}_{2} \quad=\text { kompon }
\end{gathered}
$$

3. Jarak diurutkan mulai yang terkecil hingga terbesar

4. Jika diketahui $\mathrm{k}=7$, maka pilih 7 baris dengan nilai jarak terkecil

5. Bandingkan nama kelas yang dipilih, jika terdapat kelas Normal lebih banyak dari pada kelas yang lain maka citra uji terkategori kelas 
normal. Jika kelas Benign lebih banyak kemunculannya maka citra uji tergolong kelas benign. Begitupun jika paling banyak malignant, maka citra terklasifikasi sebagai kelas malignant.

\section{HASIL DAN PEMBAHASAN}

\section{A. Data Uji Coba}

Data ujicoba terdiri dari tiga kelas, berju mlah 15 citra. Dataset diambil dari MIAS (Mammographics Image Analysis Society). Hasil Klasifikasi berupa citra normal, jinak, dan ganas [13].

\section{B. Hasil Uji Coba}

Ujicoba dilakukan dengan cara 12 citra untuk pelatihan dan 3 citra untuk pengujian. Hasil ujicoba ditunjukkan pada Tabel 1.

TABEL 1. NILAI CIRI HIST OGRAM DENGAN MET ODE ST ATISTIK

\begin{tabular}{|r|r|r|c|r|r|r|r|}
\hline citra & mean & std & var & skew & kurto & entro & kelas \\
\hline 3 & 52.03 & 63.28 & $4.0 \mathrm{E}+03$ & 0.66 & 1.599 & 1.56 & 0 \\
\hline 7 & 49.87 & 57.91 & $3.4 \mathrm{E}+03$ & 0.64 & 1.599 & 1.56 & 0 \\
\hline 9 & 53.58 & 60.82 & $3.7 \mathrm{E}+03$ & 0.73 & 2.006 & 1.36 & 0 \\
\hline 11 & 47.93 & 52 & $2.7 \mathrm{E}+03$ & 0.54 & 1.669 & 1.36 & 0 \\
\hline 1 & 36.54 & 49.34 & $2.4 \mathrm{E}+03$ & 0.76 & 1.719 & 2.08 & 1 \\
\hline 5 & 64.49 & 61.48 & $3.8 \mathrm{E}+03$ & 0.14 & 1.269 & 1.52 & 1 \\
\hline 13 & 51.34 & 60.35 & $3.6 \mathrm{E}+03$ & 0.54 & 1.466 & 2.17 & 1 \\
\hline 15 & 40.97 & 50.29 & $2.5 \mathrm{E}+03$ & 0.55 & 1.441 & 2.32 & 1 \\
\hline 23 & 64.93 & 73.29 & $5.4 \mathrm{E}+03$ & 0.49 & 1.44 & 1.49 & 2 \\
\hline 75 & 43.95 & 53.21 & $2.8 \mathrm{E}+03$ & 0.74 & 1.968 & 1.71 & 2 \\
\hline 95 & 52.22 & 55.61 & $3.1 \mathrm{E}+03$ & 0.5 & 1.63 & 1.12 & 2 \\
\hline 105 & 69.38 & 72.57 & $5.3 \mathrm{E}+03$ & 0.23 & 1.199 & 1.72 & 2 \\
\hline $\mathrm{Ke}$
\end{tabular}

Keterangan :

Kelas 0 : Normal

Kelas $1:$ jinak

Kelas 2: ganas

Setelah didapatkan nilai-nilai ciri metode statistik, selanjutnya dilakukan klasifikasi dengan menggunakan metode $\mathrm{k}-\mathrm{NN}$.

Percobaan 1, Klasifikasi terhadap citra mammogram 'mdb017.jpg'. Langkah-langkahnya sebagai berikut :

1. Dapatkan nilai dari ciri metode statistik citra uji, ditunjukkan pada Tabel 2.
TABEL 2. NILAI CIRI STATISTIK CITRA MDB017.JPG

\begin{tabular}{rcccccc}
\hline citra & mean & std & var & skew & kurto & entro \\
\hline 17 & 30.61 & 53.81 & $2.9 \mathrm{E}+03$ & 1.41 & 3.241 & 2.05 \\
\hline
\end{tabular}

2. Hitung jarak antara nilai ciri statistik uji coba dengan ciri data pelatihan menggunakan euclidian distance. Jarak ditunjukkan pada Tabel 3.

TABEL 3. JARAK CITRA UJI DENGAN CITRA PELATIHAN MENGGUNAKAN EUCLIDIANDISTANCE

\begin{tabular}{|r|r|r|r|r|r|r|c|}
\hline citra & \multicolumn{1}{|c|}{ mean } & std & var & skew & kurto & entro & jarak \\
\hline 3 & 52.03 & 63.28 & $4.0 \mathrm{E}+03$ & 0.66 & 1.599 & 1.56 & $1.15 \mathrm{E}+03$ \\
\hline 7 & 49.87 & 57.91 & $3.4 \mathrm{E}+03$ & 0.64 & 1.599 & 1.56 & $4.90 \mathrm{E}+02$ \\
\hline 9 & 53.58 & 60.82 & $3.7 \mathrm{E}+03$ & 0.73 & 2.006 & 1.36 & $8.33 \mathrm{E}+02$ \\
\hline 11 & 47.93 & 52 & $2.7 \mathrm{E}+03$ & 0.54 & 1.669 & 1.36 & $2.12 \mathrm{E}+02$ \\
\hline 1 & 36.54 & 49.34 & $2.4 \mathrm{E}+03$ & 0.76 & 1.719 & 2.08 & $4.73 \mathrm{E}+02$ \\
\hline 5 & 64.49 & 61.48 & $3.8 \mathrm{E}+03$ & 0.14 & 1.269 & 1.52 & $9.35 \mathrm{E}+02$ \\
\hline 13 & 51.34 & 60.35 & $3.6 \mathrm{E}+03$ & 0.54 & 1.466 & 2.17 & $7.80 \mathrm{E}+02$ \\
\hline 15 & 40.97 & 50.29 & $2.5 \mathrm{E}+03$ & 0.55 & 1.441 & 2.32 & $3.77 \mathrm{E}+02$ \\
\hline 23 & 64.93 & 73.29 & $5.4 \mathrm{E}+03$ & 0.49 & 1.44 & 1.49 & $2.55 \mathrm{E}+03$ \\
\hline 75 & 43.95 & 53.21 & $2.8 \mathrm{E}+03$ & 0.74 & 1.968 & 1.71 & $8.95 \mathrm{E}+01$ \\
\hline 95 & 52.22 & 55.61 & $3.1 \mathrm{E}+03$ & 0.5 & 1.63 & 1.12 & $2.40 \mathrm{E}+02$ \\
\hline 105 & 69.38 & 72.57 & $5.3 \mathrm{E}+03$ & 0.23 & 1.199 & 1.72 & $2.44 \mathrm{E}+03$ \\
\hline
\end{tabular}

3. Diketahui $\mathrm{k}=7$, urutkan nilai jarak dari terkecil hingga terbesar. Jarak terkecil hingga terbesar ditunjukkan pada Tabel 4.

TABEL 4. PENGURUTAN JARAK TERKECIL HINGGA TERBESAR

\begin{tabular}{|c|c|c|r|c|c|c|r|}
\hline mean & \multicolumn{1}{|c|}{ std } & var & skew & kurto & entro & jarak & kelas \\
\hline 43.95 & 53.21 & $2.8 \mathrm{E}+03$ & 0.74 & 1.968 & 1.71 & $8.95 \mathrm{E}+01$ & 2 \\
\hline 47.93 & 52 & $2.7 \mathrm{E}+03$ & 0.54 & 1.669 & 1.36 & $2.12 \mathrm{E}+02$ & 0 \\
\hline 52.22 & 55.61 & $3.1 \mathrm{E}+03$ & 0.5 & 1.63 & 1.12 & $2.40 \mathrm{E}+02$ & 2 \\
\hline 40.97 & 50.29 & $2.5 \mathrm{E}+03$ & 0.55 & 1.441 & 2.32 & $3.77 \mathrm{E}+02$ & 1 \\
\hline 36.54 & 49.34 & $2.4 \mathrm{E}+03$ & 0.76 & 1.719 & 2.08 & $4.73 \mathrm{E}+02$ & 1 \\
\hline 49.87 & 57.91 & $3.4 \mathrm{E}+03$ & 0.64 & 1.599 & 1.56 & $4.90 \mathrm{E}+02$ & 0 \\
\hline 51.34 & 60.35 & $3.6 \mathrm{E}+03$ & 0.54 & 1.466 & 2.17 & $7.80 \mathrm{E}+02$ & 1 \\
\hline 53.58 & 60.82 & $3.7 \mathrm{E}+03$ & 0.73 & 2.006 & 1.36 & $8.33 \mathrm{E}+02$ & 0 \\
\hline 64.49 & 61.48 & $3.8 \mathrm{E}+03$ & 0.14 & 1.269 & 1.52 & $9.35 \mathrm{E}+02$ & 1 \\
\hline 52.03 & 63.28 & $4.0 \mathrm{E}+03$ & 0.66 & 1.599 & 1.56 & $1.15 \mathrm{E}+03$ & 0 \\
\hline 69.38 & 72.57 & $5.3 \mathrm{E}+03$ & 0.23 & 1.199 & 1.72 & $2.44 \mathrm{E}+03$ & 2 \\
\hline 64.93 & 73.29 & $5.4 \mathrm{E}+03$ & 0.49 & 1.44 & 1.49 & $2.55 \mathrm{E}+03$ & 2 \\
\hline
\end{tabular}


4. Jika diketahui nilai $\mathrm{k}=7$, maka citra uji dapat diklasifikasi pada kelas 1 yaitu jinak. Pada Tabel 5 ditunjukkan hasil ujicoba citra.

TABEL 5. HASIL UJICOBA CITRA

\begin{tabular}{|c|r|r|c|}
\hline citra & \multicolumn{1}{|c|}{$\begin{array}{c}\text { klasifikasi } \\
\text { sistem }\end{array}$} & \multicolumn{1}{c|}{$\begin{array}{c}\text { klasifikasi } \\
\text { dataset }\end{array}$} & sesuai/tidak \\
\hline mdb017 & 1 & 1 & Sesuai \\
\hline mdb029 & 0 & 0 & Sesuai \\
\hline mdb021 & 2 & 1 & Tidak \\
\hline
\end{tabular}

\section{Analisis Hasil Ujicoba}

Hasil ujicoba menunjukkan 2 citra berhasil dideteksi sesuai dengan kelasnya yaitu citra mdb017 terdeteksi sebagai kanker jinak (benign) dan citra mdb029 terdeteksi sebagai citra normal. Sedangkan citra mdb021 salah identifikasi. Hasil dari sistem menunjukkan kelas citra malignant, seharusnya citra mdb021 teridentifikasi pada kelas jinak (benign).

Penggunaan data citra pada tahap pelatihan perlu diperbanyak untuk mengetahui keakurasian sistem dalam melakukan proses klasifikasi. Selanjutnya, nilai $\mathrm{K}$ pada metode $\mathrm{k}-\mathrm{NN}$ dapat diubah untuk mengetahui kehandalan sistem.

\section{KESIMPULAN}

Metode statistik diantaranya mean, standar deviasi, variance, skewness, kurtosis dan entropy yang merupakan ciri histogram dapat digunakan untuk proses ekstraksi ciri citra. Metode k-Nearest Neighbour dengan mencari jarak terdekat menggunakan euclicidian distance dapat menunjukkan kelas dari resiko penyakit kanker payudara.

Untuk tahapan selanjutnya, ujicoba dilakukan dengan variasi pengujian dengan memperbanyak data pada tahap pelatihan dan pengujian. Citra sebaiknya juga dilakukan proses preprosesing dan segmentasi sebelum dilakukan ekstraksi ciri dengan tujuan untuk mengurangi noise, memisahkan background dari objek serta memperje las segmentasi objek.

Ekstraksi ciri dapat dilakukan dengan metode global misalnya Principal Component Analysis, Linear Discriminant Analysis, Two Dimensional Principal Component Analysis dan Two Dimensional Linear Discriminant Analysis. Sedangkan metode klasifikasi dapat digunakan Correlation Coeffisien, Nä̈ve Bayes dan Support Vector Machine. Agar sistem memiliki tampilan yang user friendly, maka akan dibuat perangkat lunak dengan desain antarmuka yang sesuai dengan kebutuhan.

\section{REFERENSI}

[1] M.McDonald, R.P.Hertz and S.W.P. Lowenthal, "The Burden of Cancer in Asia", P fizer,USA, December 2008

[2] P.B Tintu and R.Paulin,'Detect Breast Cancer using Fuzzy C Means Technique in Wisconsin Prognostic Breast Cancer (WPBC) Datasets, International Journal of Computer Application Technology and Reasearch (IJCATR), Vol 2 Issue 5, Sept-Oct 2013

[3] A.M Elsayad and H.A Elsalamony,"Diagnosis of Breast Cancer Using Decision Tree Models and SVM, International Journal of Computer Application, Vol 83 No 5 ,pp 19 - 29, December 2013

[4] G.I Salama and M.A Zeid,"Breast Cancer Diagnosis on Three Different Datasets using Multi Calssifier, International Journal of Computer and Information Technology, Vol 1 Issue 1, pp 36 - 43, September 2012

[5] Zaheeruddin, Z.A Jaffery and L. Singh,"Dectection and Shape Feature Extraction of Breast Tumor in Mammograms, in Proc of the world Congress on Engineering, Vol 2, London,UK, July 2012

[6] C.F. da Cruz, "Automatic Analysis of Mammography Images : Enhancement and Segmentation Techniques, M.Sc Thesis, Universit y of Porto, July 2011

[7] Luna-Benosa, J.C.M. Perales, R.F. Carapia and V.M.S. Garcia," Identification of Abnormalities in Mammograms Images using Methods in the Spatial Domain", Applied Mathematical Science, Vol 7 No 134, pp 6696 - 6704, September 2013

[8] K.I Satoto, O.D. Nurhayati and R.R. Isnanto,'Pattern Recognition to Detect Breast Cancer Thermogram Images Based on Fuzzy Inference System Method, IJCST, Vol 2 Issue 3, pp 485-487, September 2011

[9] B.P.U. Ivy, J.Saranya and S. Subashini,'Diagnosis of Breast Cancer", IJCSET, Vol 2 Issue 2, pp 865 - 868, February 2012

[10] I.K. Maitra, S.Nag and S.K Bandyopadhyay,'Identification of Abnormal Masses in Digital Mammography Images, International Journal of Computer Graphics, Vol 2 No 1, pp 19 - 30, May 2011

[11] S.A. Mane and V. Kuhalli, "Gabor Wavelet Analysis for Mammogram in Breast Cancer Detection", International Journal on Recent and Innovation Trends in Computing and Communication, Vol 2 Issue 4, pp 778 - 781, April 2014

[12] H.S. Sheshadri,"Detection of Breast Cancer by Mammogram Image Segmentation", CancerJournal, Vol 1 Issue 4, pp 232-234, December 2015

[13] A.F Clark (2012), The MINI MIAS Database of Mammograms $\quad\{$ ONLINE $\quad$ Available peipa.essex.ac.uk/info/mias.html

[14] Y.Permadi dan Murinto,"Aplikasi Pengolahan Citra untuk Identifikasi Kematangan Timun berdasarkan Tekstur Kulit buah menggunakan metode Ekstraksi Ciri Statistik, Jurnal Informatika, Vol 9 No 1, hal 1025 - 1038, Januari 2015

[15] H.S.Sheshadri and A. Kandaswamy,"Breast Issue Classification using Statistical Feature Extraction of Mammograms, Vol 23 no 3 , pp 105 - 207, June 2006 